\title{
Nasal colonization of methicillin resistant Staphylococcus aureus in Ethiopia: a systematic review and meta-analysis
}

\author{
Alemayehu Reta*, Abeba Mengist and Asnakew Tesfahun
}

\begin{abstract}
Background: Methicillin-resistant Staphylococcus aureus (MRSA) is one of a medically important Gram-positive bacteria, which can be harboured majorly in the nasal cavity. Risk of consequent infection in a person colonized with S. aureus as well as MRSA upsurges with time and remains insistently increased. Hence, the objective of this metaanalysis was to determine the prevalence of $S$. aureus and MRSA nasal colonization in Ethiopia at large.

Methods: PubMed, Google Scholar, Embase, Hinari, Sci Hub, Scopus, and the Directory of Open Access Journals were searched and a total of 10 studies have been selected for meta-analysis. Preferred Reporting Items for Systematic Reviews and Meta-Analyses (PRISMA) guidelines were used for the literature search strategy, selection of publications, data extraction, and the reporting of results for the review. All statistical analyses were performed using STATA version 11 software via random effects model. The pooled prevalence was presented in forest plots and figure with 95\% $\mathrm{Cl}$.

Results: A total of ten studies with 2495 nasal swab samples were included in this meta-analysis, and the overall pooled estimated prevalence of S. aureus and MRSA nasal colonization in Ethiopia were $30.90 \%$ [95\% Cl $21.81-$ 39.99\%], 10.94\% [95\% Cl 8.13-13.75\%] respectively. Subgroup analysis was also noted in different regions of Ethiopia, henceforth Oromia region ranked first 21.28\% [95\% Cl 8.22-34.35\%], followed by Amhara region 6.78\% [95\% Cl 3.02-10.54\%], whereas relatively low magnitude of MRSA colonization was demonstrated from Tigray region $4.82 \%$ [95\% Cl 2.18-7.45\%].

Conclusion: The analysis showed that the overall prevalence of S. aureus and MRSA nasal colonization in Ethiopia were comparable with the global prevalence. But a huge variation between the regions, so the Ministry of Health of Ethiopia should design appropriate decolonization program that can address the specific regional groups as well as the national population.
\end{abstract}

Keywords: Methicillin-resistant Staphylococcus aureus, Nasal colonization, Meta-analysis, Ethiopia

\section{Background}

Methicillin-resistant Staphylococcus aureus (MRSA) is one of a medically important Gram-positive bacteria, which first emerged since 1961 [1]. It is introduced to the African continent in 1978 and appeared in Ethiopia in 1987 [2, 3]. Among the body sites that harbour MRSA such as throat, perineum, skin, hairline, groin, and the axilla, the anterior nares, the most important site for

\footnotetext{
*Correspondence: retaalemayeehu@gmail.com; alemayehureta@yahoo. com; Alemayehu_Reta@dmu.edu.et

Department of Medical Laboratory Science, College of Health Sciences,
} Debre Markos University, Debre Markos, Ethiopia
MRSA colonization is the nasal cavity [4]. Nasal colonization with $S$. aureus is a vibrant process; a number of factors being responsible for the gain and loss of carriage. Risk of consequent infection in a person colonized with $S$. aureus as well as MRSA upsurges with time and remains insistently increased [5].

MRSA is defined as any strain of S. aureus that has established resistance to beta-lactam antibiotics such as Methicillin, Oxacillin, Cefoxitin and Nafcillin [6, 7]. These strains are responsible for a greater number of nosocomial infections which are tough to combat in humans [8]. MRSA has been conveyed with alarming 
frequencies worldwide, and these strains majorly unveil multi-drug resistance, that is resistant to three or more classes of antibiotics [9]. Multidrug resistance of nasal S. aureus associated with methicillin-resistant strains is of great public health concern especially in developing countries [10].

Several studies in Ethiopia have reported the rate of nasal colonization of $S$. aureus and MRSA varying from $12 \%$ to $60 \%$ and $0 \%$ to $29 \%$ respectively. Increased carriage rate was recorded among patients in both $S$. aureus and MRSA [11-20].

Elimination of nasal carriage has been reported to cause a significant reduction in the incidence of MRSA infections in the community [21]. Understanding the overall epidemiology of nasal colonization of $S$. aureus and MRSA at the country level is so significant to strengthen effective prevention and control strategies. So, this meta-analysis was aimed to summarize available data and to determine the pooled prevalence of $S$. aureus and MRSA nasal colonization in Ethiopia by conducting a meta-analysis.

\section{Methods}

\section{Study design and literature search strategy}

This study did a meta-analysis on nasal colonization of S. aureus and MRSA in Ethiopia using the best available studies. Preferred Reporting Items for Systematic Reviews and Meta-Analyses (PRISMA) guidelines were used for the literature search strategy, selection of publications, data extraction, and the reporting of results for the review [22]. Published works of literatures on nasal colonization of MRSA were reviewed using the following major databases; PubMed, Google Scholar, Embase, Hinari, Sci Hub, Scopus, and the Directory of Open Access Journals (DOAJ) and additional articles identified through other electronic sources (Google, Cochrane library and reference lists). Literature searches were conducted from July to September 2018. During a comprehensive literature search, the following search terms were used: "nasal colonization, nasal carriage, MethicillinResistant Staphylococcus aureus (MRSA), Staphylococcus aureus, S. aureus, Ethiopia". Various combinations of key terms were used through Boolean search technique. Additionally, the references cited by each eligible study were scrutinized to identify additional articles. We did not limit the search by a year of publication.

\section{Study selection and eligibility criteria}

Inclusion criteria: In this meta-analysis, we included all studies that were conducted on nasal colonization of MRSA in Ethiopia. All available studies and data were incorporated based on the following predefined eligibility criteria: Should be published and written in English, had to describe the standard microbial isolation and identification, studies should use human originated sample and should be a prospective cross-sectional study.

Exclusion criteria: Studies that used samples other than human origin and nasal swab; Studies that didn't describe the standard microbial isolation and identification techniques and studies with no full information to calculate the prevalence MRSA were excluded.

\section{Outcome of interest}

The major outcome of interest was the prevalence of MRSA and S. aureus nasal swab isolates. The prevalence was calculated by dividing both the numbers of MRSA and $S$. aureus isolates to the total number of nasal swab samples.

\section{Quality assessment and critical appraisal}

In this meta-analysis, the qualities of each article were assessed by using a critical appraisal tool for use in systematic reviews for prevalence study [23]. The employed methods for MRSA isolation and eligibility of the identified articles were also assessed by all authors and disagreements among reviewers were fixed accordingly with a discussion. In addition, a modified version of the Newcastle-Ottawa Scale for the cross-sectional study was used to evaluate the quality of studies [24].

\section{Data extraction}

Data from appropriate studies were pull out independently by authors and potted into a spreadsheet. Inconsistencies were resolved by unanimity. For each of the encompassed studies, the following information was extracted; the name of the author, publication year, study area, study period, study design, study population, number of samples, number of $S$. aureus isolates, number of MRSA, the prevalence of $S$. aureus and prevalence of MRSA.

\section{Data analysis and synthesis}

The extracted data were entered into the computer through command window of STATA software version 11 and the data manipulation and all statistical analysis were performed using STATA version 11. A random effect model was used to estimate the overall pooled prevalence of $S$. aureus and MRSA and this model was recommended to handle heterogeneity between studies for meta-analysis [25-27]. The $\mathrm{I}^{2}$ statistical test was used to check heterogeneity, and it quantified the percentage of total variation in the study [28]. $\mathrm{I}^{2}$ test ranges from $0 \%$ (observed heterogeneity) to $100 \%$ (significant heterogeneity). A $\mathrm{p}$ value $<0.05$ was used to declare heterogeneity $[29,30]$. In the current metaanalysis, $\mathrm{I}^{2}$ values were found to be high $(>75 \%)$. This 
scenario leads to use a random effects model with 95\% CIs to avoid the significant heterogeneity. Furthermore, the presence of heterogeneity was also assessed by subgroup analysis and meta-regression. Visual assessment of publication bias was shown using funnel plot. Asymmetry of the funnel plot is an indicator of publication bias [22]. To check potential publication bias (small study bias), Egger's and Begg's tests were performed [31]. Also, the sensitivity analysis was done to assess whether the pooled prevalence estimates were prejudiced by individual studies.

\section{Result}

Selection and identification of studies

The process of identifying the relevant articles for inclusion in this meta-analysis is represented graphically in Fig. 1. A total of 732 studies were identified through an electronic database search. We added 101 additional articles identified through other electronic sources (Google, Cochrane library and reference lists). Of these studies, 589 were excluded after reviewing their title and abstracts, 119 were found to be duplicates, and 115 were disregarded because the abstracts or full-text information did not directly relate to the topic of interest i.e. nasal

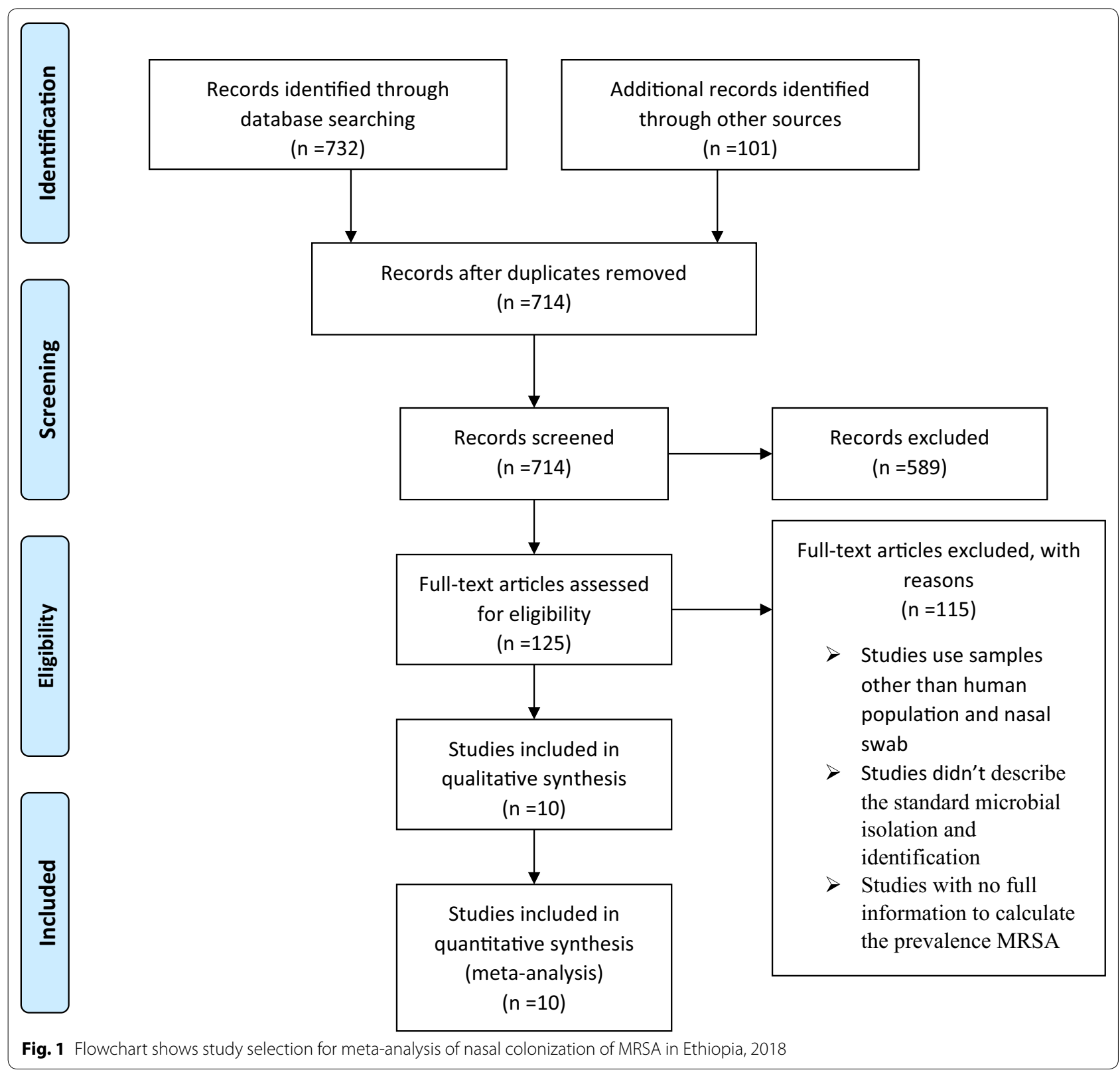


colonization of MRSA in Ethiopia. Finally, 10 unique articles fulfilled our eligibility criteria and were enrolled for meta-analysis (Fig. 1).

\section{Characteristics of included studies}

A total of ten studies with 2495 nasal swab samples were included in this meta-analysis was summarized in Table 1. The studies were conducted from 2003 to 2018 in different regions of the country. Among 10 studies, four of them [11, 16, 18, 19] were conducted in Amhara region, three studies $[12,14,20]$ were in the Oromia region, and the other three studies $[13,15,17]$ were in Tigray regional state of the country, no data was obtained from other regions (Benishangul-Gumuz, Gambella, Somali, SNNP (Southern Nations Nationalities and People), Afar, Dire Dawa and Addis Ababa). All studies were a cross-sectional study conducted on nasal colonization of MRSA in Ethiopia. The study with a minimum and a maximum nasal swab sample was conducted in Oromia and Amhara region, respectively $[14,18]$. In addition, out of all studies enrolled in this meta-analysis eight studies [11, 13-16, 18-20] were conducted among patients while the remaining two studies $[12,17]$ were conducted from apparently healthy individuals (Table 1).

\section{Nasal colonization of S. aureus}

The pooled prevalence using the fixed effect model revealed significant heterogeneity between the studies. Hereafter, we performed the analysis using the random effects model. Using random effects model, the estimated pooled prevalence of nasal colonization of $S$. aureus stated by the ten studies was $30.90 \%$ [95\% CI $21.81-$ $39.99 \%$ ] with significant heterogeneity between studies $\left(\mathrm{I}^{2}=100 \%, \mathrm{p}<0.001\right)$. The pooled prevalence of nasal colonization of S. aureus offered using forest plot (Fig. 2). To assess the potential heterogeneity between studies, subgroup analysis by study area was conducted. Of the ten studies, the highest expected nasal colonization of $S$. aureus prevalence found in studies showed in Oromia region $47.74 \%$ [95\% CI $40.72-54.77 \%$ ], $\mathrm{I}^{2}=99.8 \%$, $\mathrm{p}<0.001$, followed by studies showed in Amhara region, was $25.82 \%$ [ $95 \%$ CI $11.08-40.57 \%$ ], $\mathrm{I}^{2}=100 \%, \mathrm{p}<0.001$ (Fig. 3).

\section{Nasal colonization of MRSA}

As shown from Fig. 4, the overall pooled prevalence of nasal colonization of MRSA was 10.94\% [95\% CI 8.13$13.75 \%], \mathrm{I}^{2}=100 \%, \mathrm{p}<0.001$. Subgroup analysis was also noted in different regions of Ethiopia, henceforth Oromia region ranked first $21.28 \%$ [95\% CI 8.22-34.35\%], $\mathrm{I}^{2}=99.9 \%, \mathrm{p}<0.001$, followed by Amhara region $6.78 \%$ [95\% CI $3.02-10.54 \%], \mathrm{I}^{2}=100 \%, \mathrm{p}<0.001$, whereas relatively low magnitude of MRSA colonization were demonstrated from Tigray region 4.82\% [95\% CI 2.18$7.45 \%], \mathrm{I}^{2}=100 \%, \mathrm{p}<0.001$ (Figs. 5 and 6 ).

\section{Investigation of heterogeneity}

In this meta-analysis, the value of $\mathrm{I}^{2}$ indicates a significant high heterogeneity, so we adjust this by using random effect model and the source of heterogeneity was investigated using meta-regression model using publication year and the number of a sample as covariates. The result of meta-regression analysis revealed that both covariates were not statistically significant for the presence of heterogeneity (Table 2).

\section{Publication bias}

The presence of publication bias was assessed using Begg's and Egger's tests, showing no statistical significance for estimating the prevalence of nasal colonization of S. aureus and MRSA (Table 3, Figs. 7 and 8).

\section{Sensitivity analysis}

The result of sensitivity analysis using random effects model suggested that no single study improperly influenced the overall prevalence estimate of nasal colonization of S. aureus and MRSA (Figs. 9 and 10).

\section{Discussion}

We conducted this meta-analysis to estimate the overall pooled prevalence of nasal colonization of S. aureus and MRSA in Ethiopia. Ten unique articles which fulfilled our eligibility criteria were included and enrolled for metaanalysis. After analysis, the overall estimated pooled prevalence of nasal colonization of $S$. aureus and MRSA in Ethiopia were $30.90 \%$ [95\% CI 21.81-39.99\%]), 10.94\% [95\% CI 8.13-13.75\%]) respectively. The overall prevalence of nasal colonization of $S$. aureus indicated in this meta-analysis is in line with a meta-analysis conducted in Iran (22.7\% [95\% CI 19.3-26.6]). The pooled estimate prevalence of nasal colonization of MRSA in this metaanalysis is lower than a meta-analysis conducted in Iran (32.8\% (95\% CI 26.0-40.4) [32] and Egypt (32\%) [33], and relatively higher than a systematic review done in Europe and the United States of America (1.8\% [95\% CI 1.34$2.50 \%]$ [34], Moreover, it is in agreement with a study done in Nigeria (11\%) [35]. The possible explanations for the above variations could be due to methodological differences (i.e., Microbiological isolation and detection techniques), variation in sociodemographic characteristics, economic, and health service utilization.

In this study, we also performed subgroup analysis based on the regions of the country where the studies were conducted. The findings of the subgroup analysis indicated that extreme variability was observed in both the prevalence of nasal colonization of $S$. aureus and 


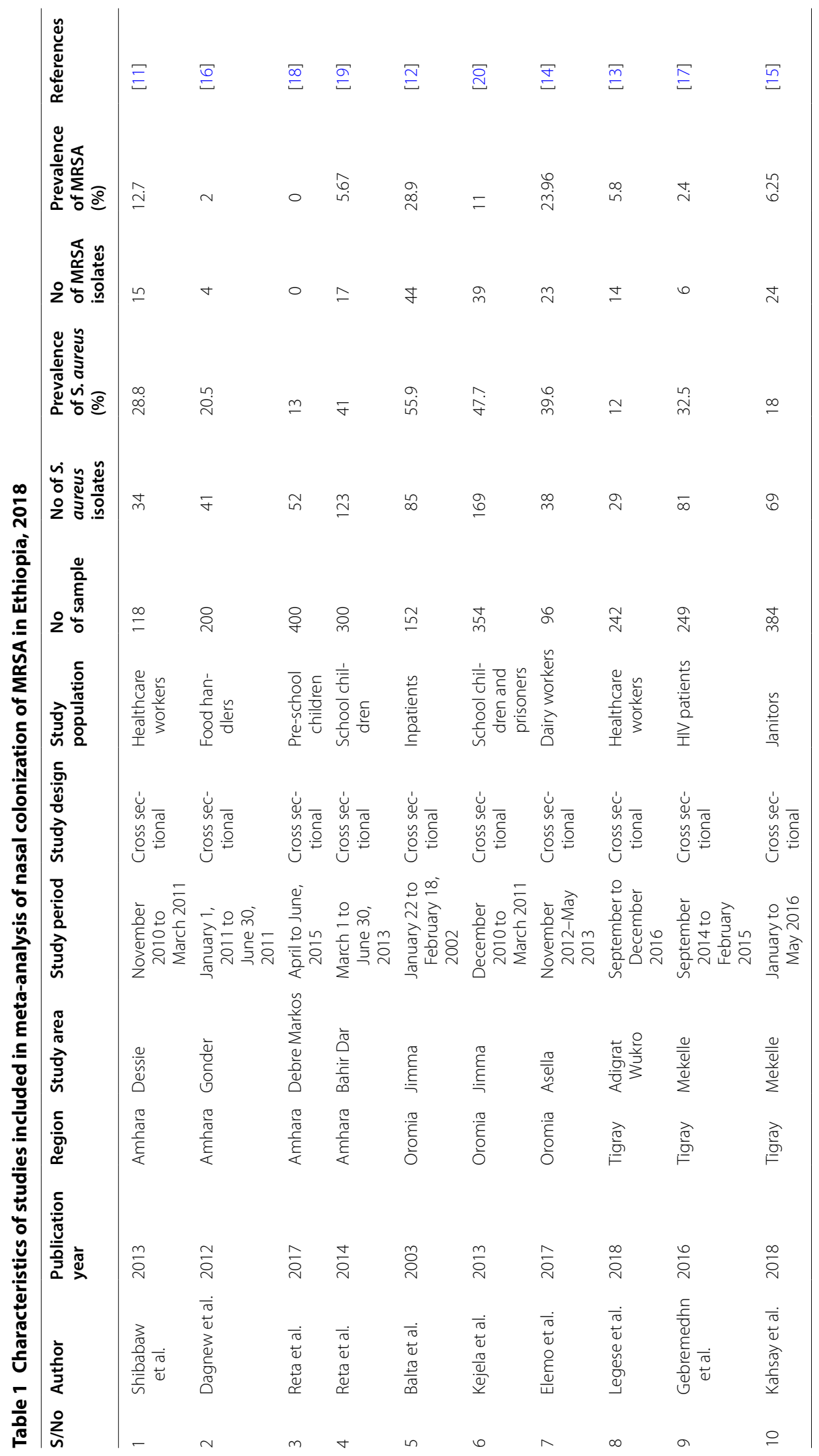




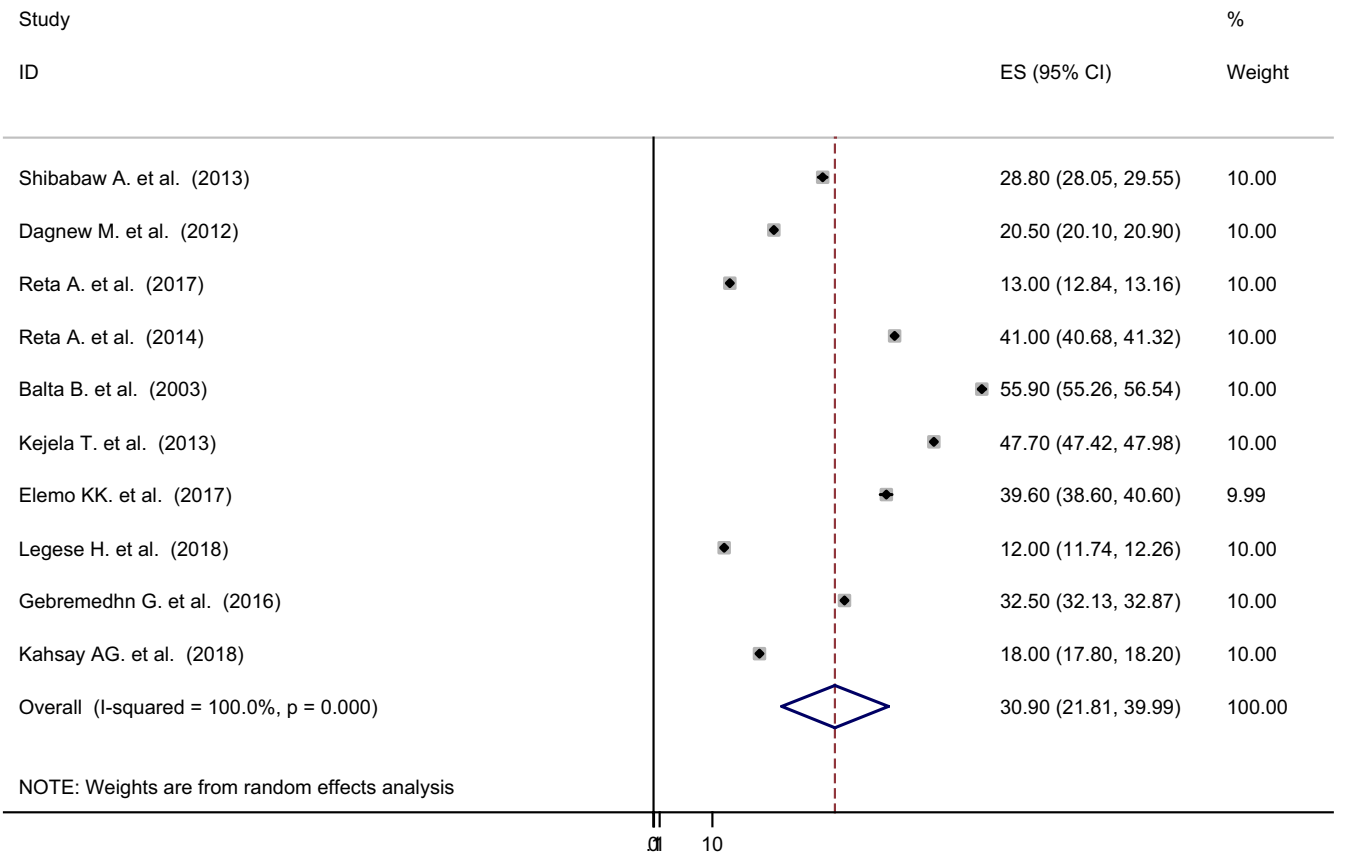

Fig. 2 Forest plot showing the pooled prevalence of nasal colonization of S. aureus in 10 studies in Ethiopia, 2018

Study

ID
ES $(95 \% \mathrm{Cl})$

$\%$

Weight
Amhara

Shibabaw A. et al. (2013)

Dagnew M. et al. (2012)

Reta A. et al. (2017)

Reta A. et al. (2014)

Subtotal $(\mathrm{I}$-squared $=100.0 \%, p=0.000$ )

Oromia

Balta B. et al. (2003)

Kejela T. et al. (2013)

Elemo KK. et al. (2017)

Subtotal $(\mathrm{l}$-squared $=99.8 \%, \mathrm{p}=0.000$ )

Tigray

Legese H. et al. (2018)

Gebremedhn G. et al. (2016)

Kahsay AG. et al. (2018)

Subtotal (I-squared $=100.0 \%, p=0.000)$

Overall (I-squared $=100.0 \%, p=0.000)$

NOTE: Weights are from random effects analysis

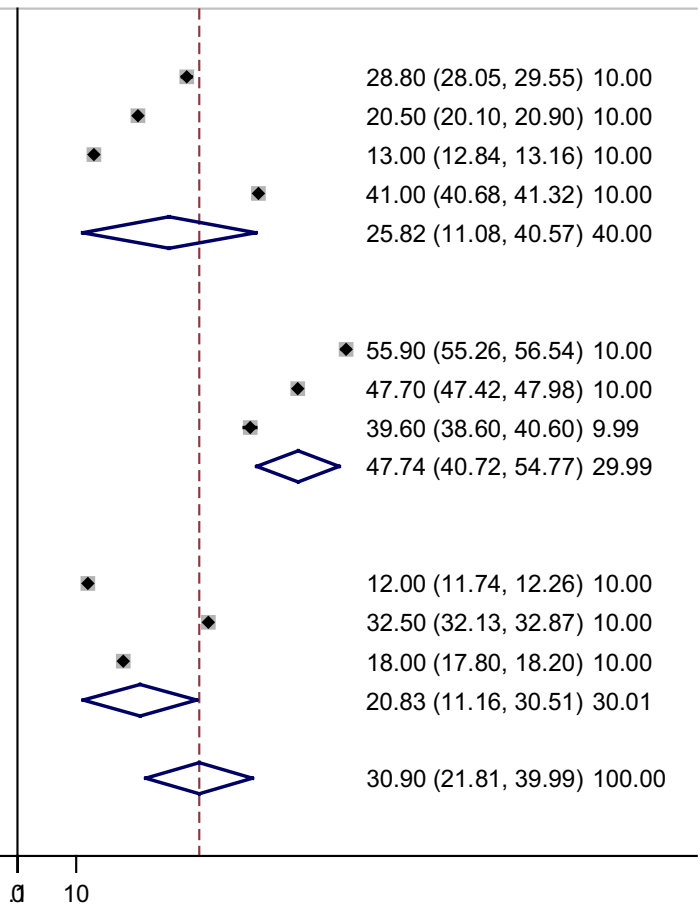

Fig. 3 Subgroup analysis by regions on the prevalence of nasal colonization of S. aureus in 10 studies in Ethiopia, 2018 
Study

ID

ES $(95 \% \mathrm{Cl})$

Weight

Shibabaw A. et al. (2013)

Dagnew M. et al. (2012)

Reta A. et al. (2014)

Balta B. et al. (2003)

Kejela T. et al. (2013)

Elemo KK. et al. (2017)

Legese H. et al. (2018)

Gebremedhn G. et al. (2016)

Kahsay AG. et al. (2018)

Overall (I-squared $=100.0 \%, p=0.000)$

NOTE: Weights are from random effects analysis

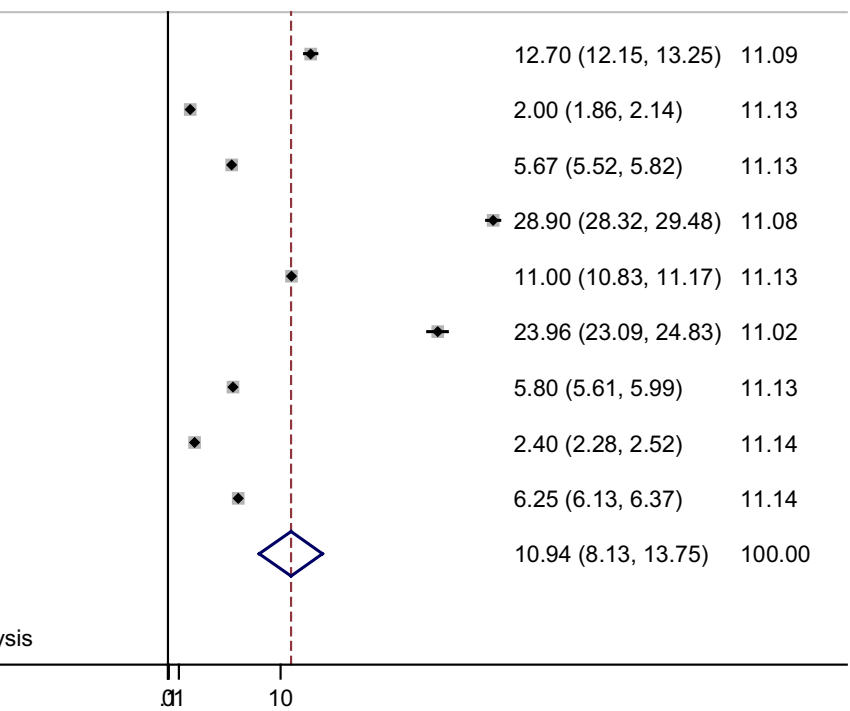

Fig. 4 Forest plot showing the pooled prevalence of nasal colonization of MRSA in 9 studies in Ethiopia, 2018

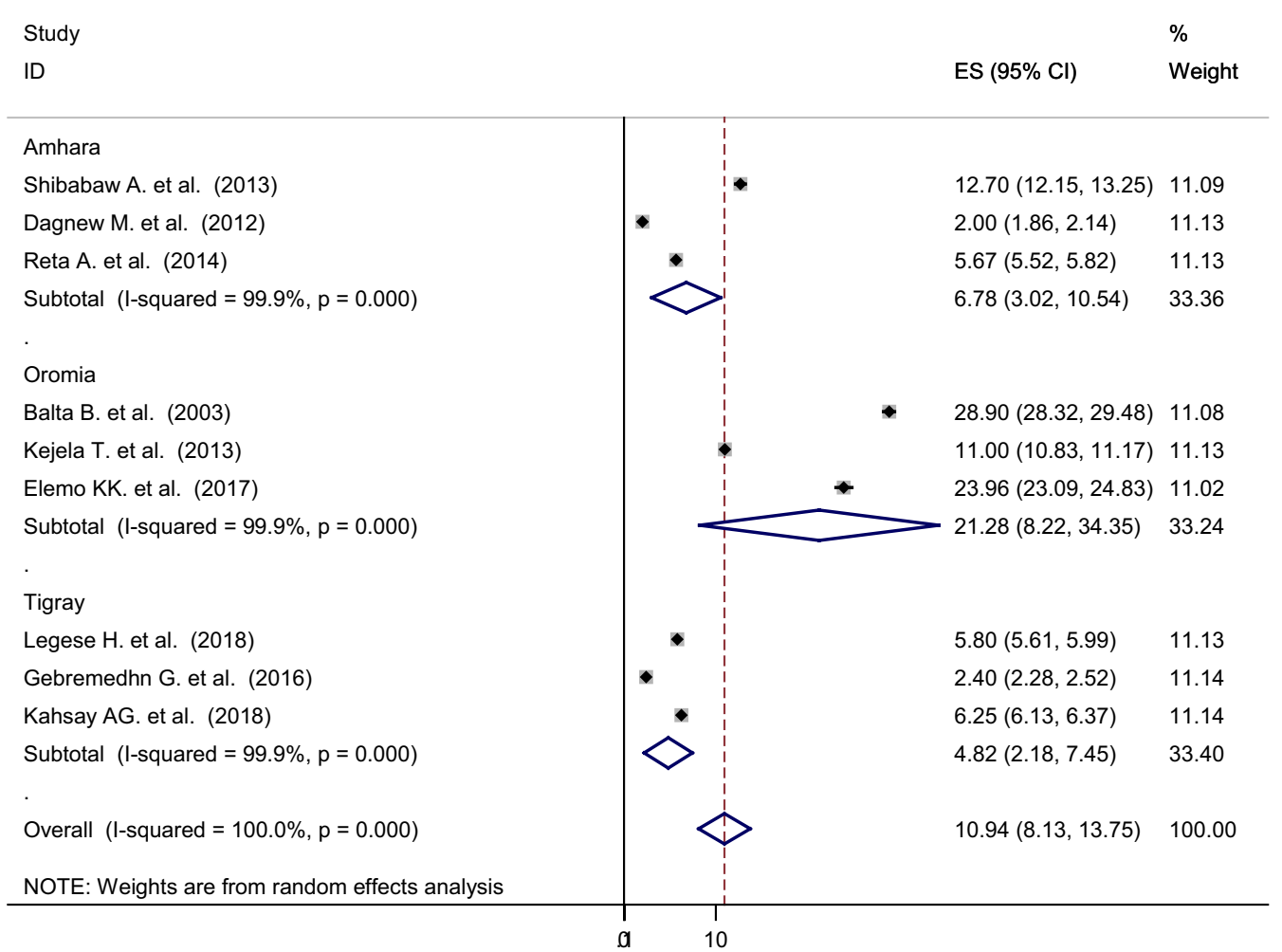

Fig. 5 Subgroup analysis by regions on the prevalence of nasal colonization of MRSA in 9 studies in Ethiopia, 2018 


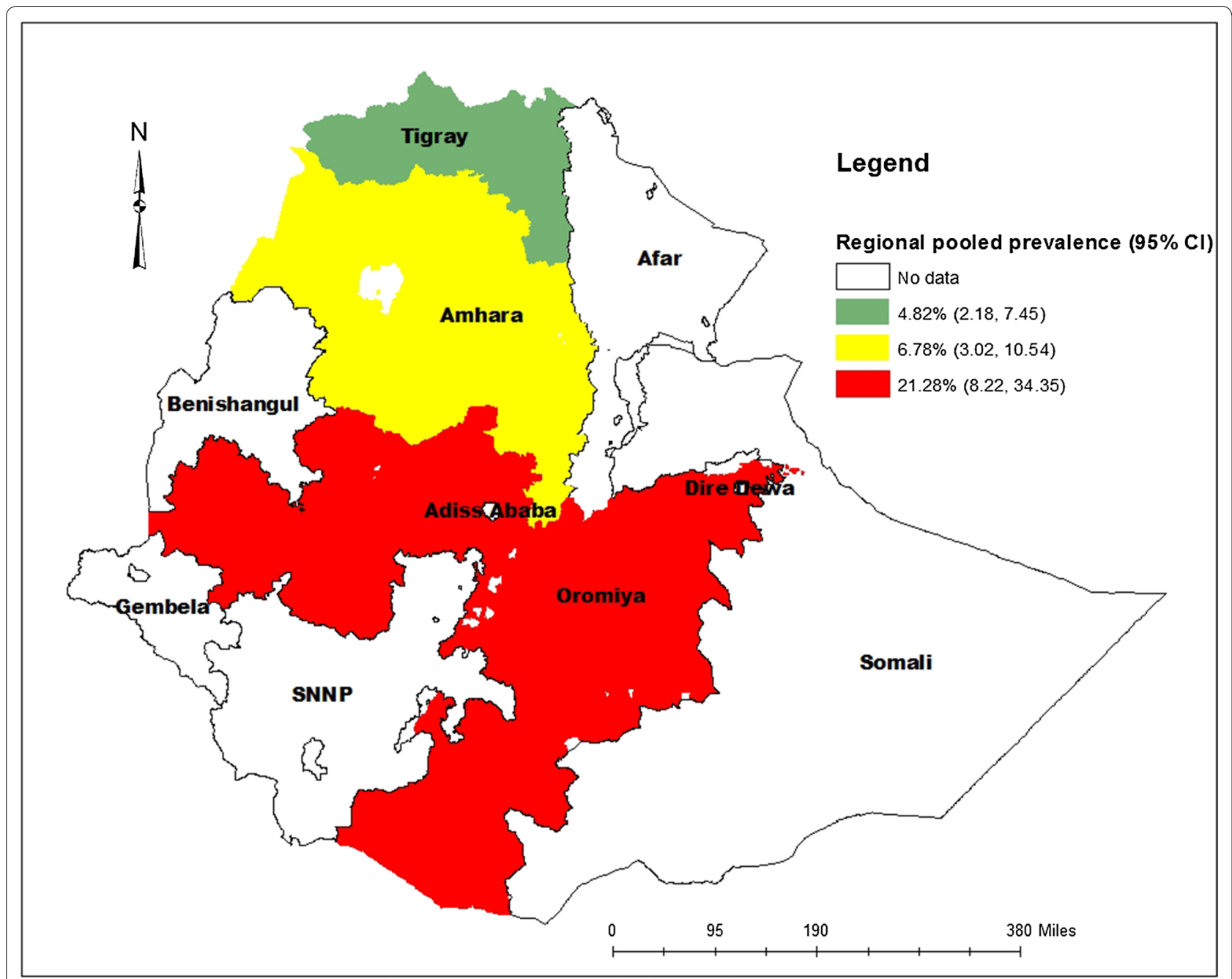

Fig. 6 Prevalence of nasal colonization of MRSA in different regions of Ethiopia, 2018

Table 2 Meta-regression analysis of factors with heterogeneity of the prevalence of nasal colonization of S. aureus in Ethiopia, 2018

\begin{tabular}{|c|c|c|c|c|c|c|}
\hline Heterogeneity source & Coefficients & Std. err. & $t$ & $P$ value & $95 \%$ conf. interval & \\
\hline Publication year & -2.358079 & 2.81955 & -0.84 & 0.431 & -9.025255 & 4.309097 \\
\hline No of sample & -0.0114633 & 0.077581 & -0.15 & 0.887 & -0.1949132 & 0.1719866 \\
\hline
\end{tabular}

Table 3 P-value for Begg's and Egger's test for nasal colonization of S. aureus and MRSA, 2018

\begin{tabular}{lll}
\hline Tests & P value & \\
\cline { 2 - 3 } & $\begin{array}{l}\text { Nasal colonization of } \boldsymbol{S} . \\
\text { aureus }\end{array}$ & $\begin{array}{l}\text { Nasal } \\
\text { colonization } \\
\text { of MRSA }\end{array}$ \\
\hline Begg's & 0.721 & 0.251 \\
Egger's & 0.353 & 0.167 \\
\hline
\end{tabular}

MRSA across the regions of the country. The highest (47.74\%, 21.28\%) prevalence of nasal colonization of $S$. aureus and MRSA respectively was reported from the Oromia region, whereas the lowest $(20.83 \%, 4.82 \%)$ prevalence of nasal colonization of $S$. aureus and MRSA was reported from Tigray region. The possible explanation for this variation might be due to the cultural variation, the difference in health infrastructure and health policy implementation across the regions of the country. 


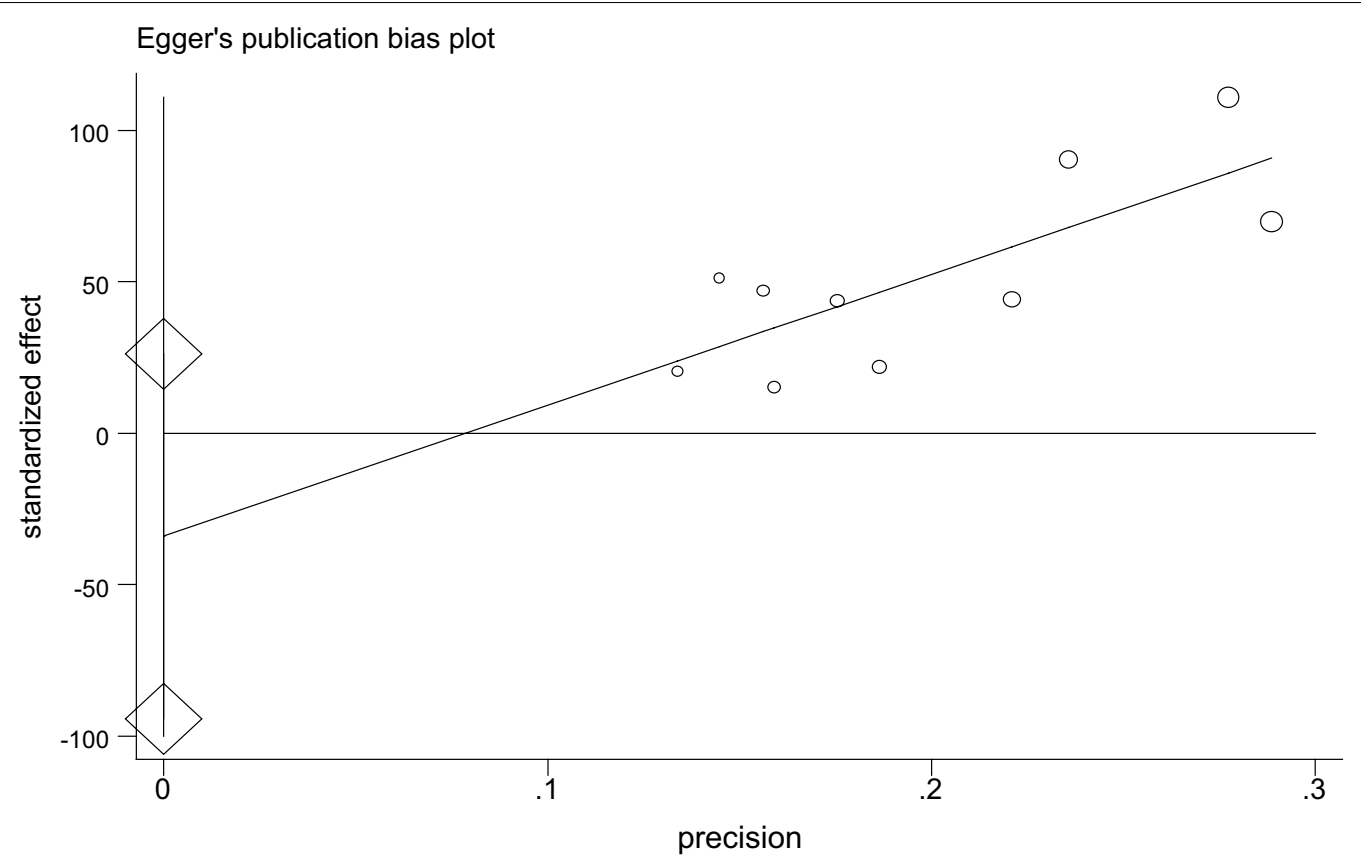

Fig. 7 The result of Egger's publication bias test of 10 studies on nasal colonization of S. aureus, 2018

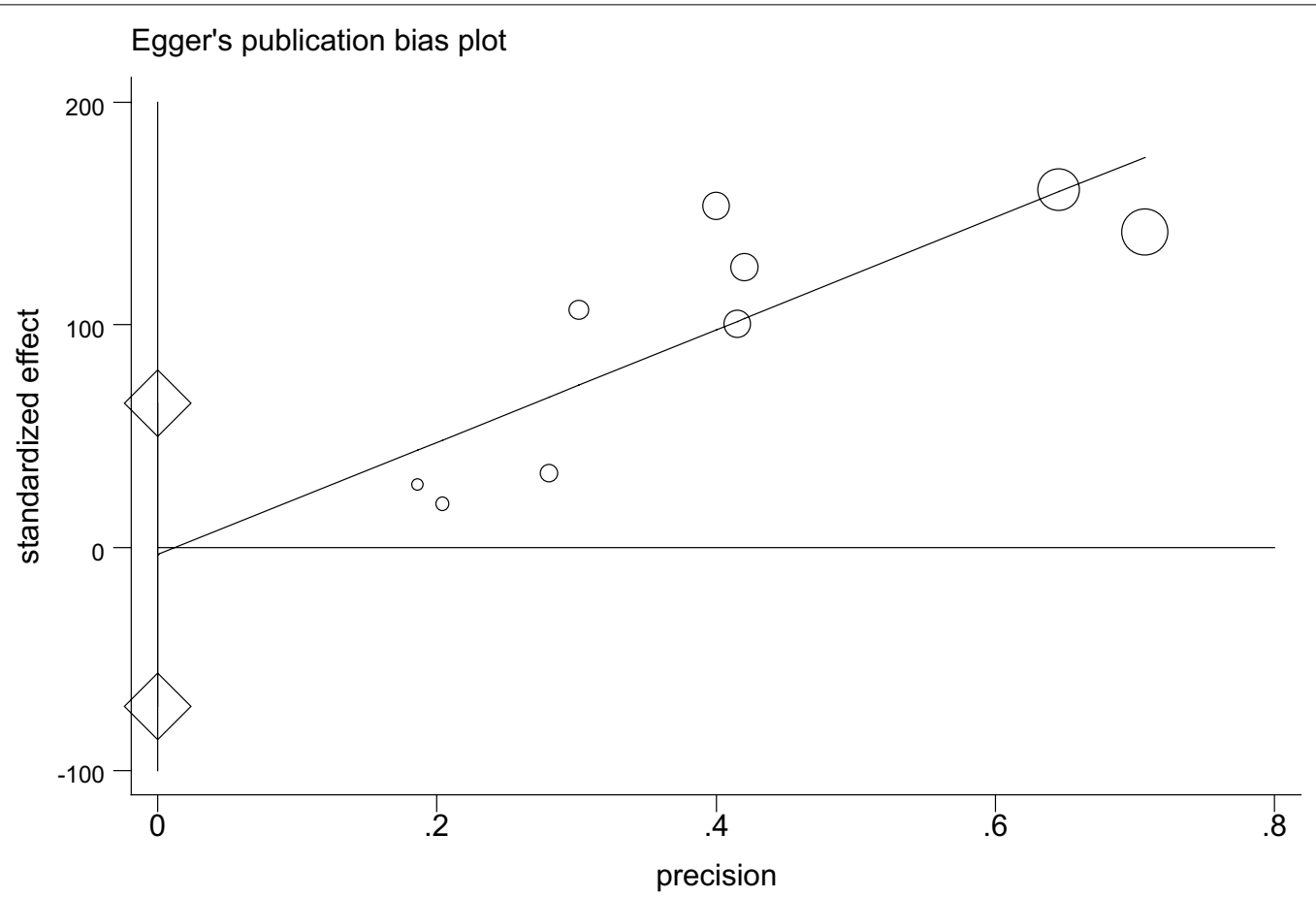

Fig. 8 The result of Egger's publication bias test of 9 studies on nasal colonization of MRSA, 2018

\section{Limitations of the study}

Due to the absence of similar and related factors, we were unable to perform factor analysis and examine the pooled odds ratios, even if there are a number of factors in each study such as age, sex, socioeconomic status, use of antibiotics, hospitalization, recurrent acute 

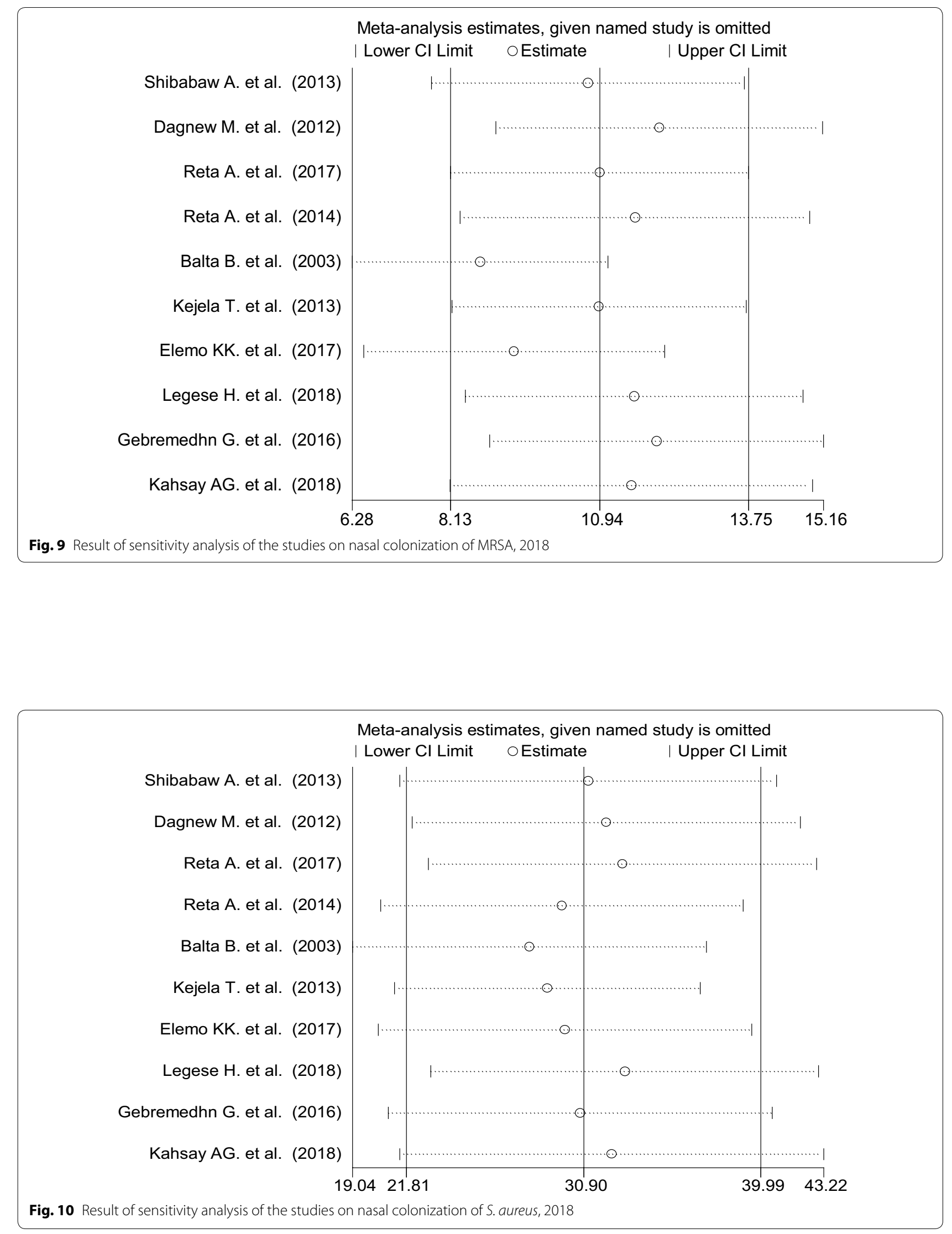
otitis media, hygienic practice of the hand and the like. However, this review has delivered valuable information concerning the pooled estimate prevalence of nasal colonization of $S$. aureus and MRSA.

\section{Conclusions and recommendations}

This meta-analysis demonstrates that the pooled estimated prevalence of nasal colonization of $S$. aureus and MRSA in Ethiopia was relatively in a comparable prevalence with the total nasal colonization of $S$. aureus and MRSA as a whole in the human population. But, when we observed the pooled estimate prevalence of each $(S$. aureus and MRSA) in different regions of Ethiopia, it has extreme variation. Thus, to contest the burden of nasal colonization of $S$. aureus and MRSA in particular, the following concerns should be well thought-out at the national level, such as adopting safety protocols and implementing proper decolonization policies in a regional base.

Finally, in Ethiopia, conducting such type of study will give additional input for program planners and policy makers working in the area of infectious disease and also it will help clinicians to give empirical treatment.

\section{Abbreviations}

Cl: confidence interval; DOAJ: Directory of Open Access Journals; MRSA: methicillin-resistant Staphylococcus aureus; PRISMA: Preferred Reporting Items for Systematic Reviews and Meta-Analyses; SNNP: Southern Nations Nationalities and People; STATA: statistics and data.

\section{Acknowledgements}

We would like to thank Mr. Getiye Dejenu for his support during statistical analysis (STATA).

\section{Authors' contributions}

AR carried out conceptualization, formal statistical analysis, development of methodology, curation of data, drafted the manuscript, revising it critically for important intellectual content, given final approval of the version to be published. AM and AT carried out curation of data, revising it critically and searching literatures. All authors read and approved the final manuscript.

\section{Funding}

Not applicable.

\section{Availability of data and materials}

Data sharing is not applicable to this article as no datasets were generated or analyzed during the current study.

\section{Ethics approval and consent to participate}

Not applicable.

\section{Consent for publication}

Not applicable.

\section{Competing interests}

The authors declare that they have no competing interests.

Received: 22 March 2019 Accepted: 28 August 2019

Published online: 05 September 2019
References

1. Colley E, McNicol M, Bracken P. Methicillin-resistant Staphylococci in a general hospital. Lancet. 1965;285(7385):595-7.

2. Scragg JN, Appelbaum P, Govender D. The spectrum of infection and sensitivity of organisms isolated from African and Indian children in a Durban hospital. Trans R Soc Trop Med Hyg. 1978;72(4):325-8.

3. Geyid A, Lemeneh Y. The incidence of methicillin resistant S. aureus strains in clinical specimens in relation to their beta-lactamase producing and multiple-drug resistance properties in Addis Abeba. Ethiop Med J. 1991;29(4):149-61.

4. Foster TJ. The Staphylococcus aureus "superbug". J Clin Investig. 2004;114(12):1693-6.

5. Gupta K, Martinello RA, Young M, Strymish J, Cho K, Lawler E. MRSA nasal carriage patterns and the subsequent risk of conversion between patterns, infection, and death. PLOS ONE. 2013;8(1):e53674.

6. Lowy FD. Antimicrobial resistance: the example of Staphylococcus aureus. J Clin Investig. 2003;111(9):1265-73.

7. Taiwo S, Onile B, Akanbi A II. Methicillin-resistant Staphylococcus aureus (MRSA) isolates in Ilorin, Nigeria. Afr J Clin Exp Microbiol. 2004;5(2):189-97.

8. Lin J, Morrison D, Oriade D. The discovery of a multi-resistant Staphylococcus haemolyticus clone in the hospital and community environment in south western Nigeria. Ostomy Wound Manage. 2005;51(1):67-70.

9. Simmons S. Effects of selective patient screening for MRSA on overall MRSA hospital-acquired infection rates. Crit Care Nurs Q. 2011;34(1):18-24.

10. Onanuga A, Oyi A, Olayinka B, Onaolapo J. Prevalence of communityassociated multi-resistant Staphylococcus aureus among healthy women in Abuja, Nigeria. Afr J Biotechnol. 2005;4(9):942-5.

11. Shibabaw A, Abebe T, Mihret A. Nasal carriage rate of methicillin resistant Staphylococcus aureus among Dessie Referral Hospital health care workers; Dessie, Northeast Ethiopia. Antimicrob Resist Infect Control. 2013;2(1):25.

12. Balta B, Derbie F. Nasal carriage of methicillin resistant Staphylococcus aureus strains among inpatients of Jimma hospital, South Western Ethiopia. Ethiop J Health Sci. 2003;13(2):107-15.

13. Legese H, Kahsay AG, Kahsay A, Araya T, Adhanom G, Muthupandian S, et al. Nasal carriage, risk factors and antimicrobial susceptibility pattern of methicillin resistant Staphylococcus aureus among healthcare workers in Adigrat and Wukro hospitals, Tigray, Northern Ethiopia. BMC Res Notes. 2018;11(1):250.

14. Elemo KK, Sisay T, Shiferaw A, Fato MA. Prevalence, risk factors and multidrug resistance profile of Staphylococcus aureus isolated from bovine mastitis in selected dairy farms in and around Asella town, Arsi Zone, South Eastern Ethiopia. Afr J Microbiol Res. 2017;11(45):1632-42.

15. Kahsay AG, Hagos DG, Abay GK, Mezgebo TA. Prevalence and antimicrobial susceptibility patterns of methicillin-resistant Staphylococcus aureus among janitors of Mekelle University, North Ethiopia. BMC Res Notes. 2018;11(1):294

16. Dagnew M, Tiruneh M, Moges F, Tekeste Z. Survey of nasal carriage of Staphylococcus aureus and intestinal parasites among food handlers working at Gondar University, Northwest Ethiopia. BMC Public Health. 2012;12(1):837.

17. Gebremedhn G, Gebremariam TT, Wasihun AG, Dejene TA, Saravanan M. Prevalence and risk factors of methicillin-resistant Staphylococcus aureus colonization among HIV patients in Mekelle, Northern Ethiopia. SpringerPlus. 2016:5(1):877.

18. Reta A, Wubie M, Mekuria G. Nasal colonization and antimicrobial susceptibility pattern of Staphylococcus aureus among pre-school children in Ethiopia. BMC Res Notes. 2017;10(1):746.

19. Reta A, Gedefaw L, Sewunet T, Beyene G. Nasal carriage, risk factors and antimicrobial susceptibility pattern of methicillin resistant Staphylococcus aureus among school children in Ethiopia. J Med Microbiol Diagn. 2015:4(1):1.

20. Kejela T, Bacha K. Prevalence and antibiotic susceptibility pattern of methicillin-resistant Staphylococcus aureus (MRSA) among primary school children and prisoners in Jimma Town, Southwest Ethiopia. Ann Clin Microbiol Antimicrob. 2013;12(1):11.

21. Halablab M, Hijazi S, Fawzi M, Araj G. Staphylococcus aureus nasal carriage rate and associated risk factors in individuals in the community. Epidemiol Infect. 2010;138(5):702-6. 
22. Liberati A, Altman DG, Tetzlaff J, Mulrow C, Gøtzsche PC, loannidis JP, et al. The PRISMA statement for reporting systematic reviews and meta-analyses of studies that evaluate health care interventions: explanation and elaboration. PLoS Med. 2009;6(7):e1000100.

23. Munn Z, Moola S, Riitano D, Lisy K. The development of a critical appraisal tool for use in systematic reviews addressing questions of prevalence. Int J Health Policy Manage. 2014;3(3):123.

24. Modesti PA, Reboldi G, Cappuccio FP, Agyemang C, Remuzzi G, Rapi S, et al. Panethnic differences in blood pressure in Europe: a systematic review and meta-analysis. PLoS ONE. 2016;11(1):e0147601.

25. George BJ, Aban IB. An application of meta-analysis based on DerSimonian and Laird method. Berlin: Springer; 2016.

26. IntHout J, loannidis JP, Borm GF. The Hartung-Knapp-Sidik-Jonkman method for random effects meta-analysis is straightforward and considerably outperforms the standard DerSimonian-Laird method. BMC Med Res Methodol. 2014;14(1):25.

27. Knol M, Twisk JW, Beekman AT, Heine R, Snoek FJ, Pouwer F. Depression as a risk factor for the onset of type 2 diabetes mellitus. A meta-analysis. Diabetologia. 2006;49(5):837.

28. Higgins JP, Thompson SG. Quantifying heterogeneity in a meta-analysis. Stat Med. 2002;21(11):1539-58.

29. Park M, Katon WJ, Wolf FM. Depression and risk of mortality in individuals with diabetes: a meta-analysis and systematic review. Gen Hosp Psychiatry. 2013;35(3):217-25.

30. Wang J, Wu X, Lai W, Long E, Zhang X, Li W, et al. Prevalence of depression and depressive symptoms among outpatients: a systematic review and meta-analysis. BMJ Open. 2017;7(8):e017173.
31. Sarokhani D, Delpisheh A, Veisani Y, Sarokhani MT, Manesh RE, Sayehmiri K. Prevalence of depression among university students: a systematic review and meta-analysis study. Depress Res Treat. 2013;2013:373857. https://doi.org/10.1155/2013/373857.

32. Emaneini M, Jabalameli F, Rahdar H, Leeuwen WBV, Beigverdi R. Nasal carriage rate of methicillin resistant Staphylococcus aureus among Iranian healthcare workers: a systematic review and meta-analysis. Revista da Sociedade Brasileira de Medicina Tropical. 2017;50(5):590-7.

33. Sadek SEA, Abdelrahman AT, Abdelkader NG, Abdelrahim M. Clinical and microbiological effect of linezolid on methicillin-resistant Staphylococcus aureus (MRSA) colonization in healthcare workers in Egypt. Middle East J Sci Res. 2013;15(10):1440-9.

34. Dulon M, Peters C, Schablon A, Nienhaus A. MRSA carriage among healthcare workers in non-outbreak settings in Europe and the United States: a systematic review. BMC Infect Dis. 2014;14(1):363.

35. Ohagim IP, Nyong EE, Moses AE. Methicillin-resistant Staphylococcus aureus nasal carriage among surgical patients, patient relatives and healthcare workers in a teaching hospital in Uyo, Southsouth Nigeria. J Adv Microbiol. 2018;8(1):1-11.

\section{Publisher's Note}

Springer Nature remains neutral with regard to jurisdictional claims in published maps and institutional affiliations.
Ready to submit your research? Choose BMC and benefit from:

- fast, convenient online submission

- thorough peer review by experienced researchers in your field

- rapid publication on acceptance

- support for research data, including large and complex data types

- gold Open Access which fosters wider collaboration and increased citations

- maximum visibility for your research: over $100 \mathrm{M}$ website views per year

At BMC, research is always in progress.

Learn more biomedcentral.com/submissions 